Article

\title{
A Long-Term Observation on the Possible Adverse Effects in Japanese Adolescent Girls after Human Papillomavirus Vaccination
}

\author{
Akiyo Hineno ${ }^{1,2}$ and Shu-Ichi Ikeda $1,3, *$ D \\ 1 Intractable Disease Care Center, Shinshu University Hospital, Matsumoto 390-0802, Japan; \\ hineno@shinshu-u.ac.jp \\ 2 Department of Medicine (Neurology and Rheumatology), School of Medicine, Shinshu University, \\ Matsumoto 390-8621, Japan \\ 3 Ikeda Medicine and Neurology Clinic, Azumino 399-8205, Japan \\ * Correspondence: shu-ichi@ikeda-mnc.jp; Tel.:+81-263-31-6773; Fax:+81-263-31-6783
}

check for updates

Citation: Hineno, A.; Ikeda, S.-I. A Long-Term Observation on the Possible Adverse Effects in Japanese Adolescent Girls after Human Papillomavirus Vaccination. Vaccines 2021, 9, 856. https://doi.org/ $10.3390 /$ vaccines 9080856

Academic Editor: Gloria Calagna

Received: 10 June 2021

Accepted: 30 July 2021

Published: 4 August 2021

Publisher's Note: MDPI stays neutral with regard to jurisdictional claims in published maps and institutional affiliations.

Copyright: (c) 2021 by the authors. Licensee MDPI, Basel, Switzerland. This article is an open access article distributed under the terms and conditions of the Creative Commons Attribution (CC BY) license (https:// creativecommons.org/licenses/by/ $4.0 /)$.

\begin{abstract}
In Japan, a significant number of adolescent females noted unusual symptoms after receiving the human papillomavirus (HPV) vaccination, of which the vast majority of them were initially diagnosed with psychiatric illnesses because of the absence of pathologic radiological images and specific abnormalities in laboratory test results. Later these symptoms were thought to be adverse effects of HPV vaccination. However, a causal link between HPV vaccination and the development of these symptoms has not been demonstrated. Between June 2013 and March 2021, we examined 200 patients who noted various symptoms after HPV vaccination. In total, 87 were diagnosed with HPV vaccination-related symptoms based on our proposed diagnostic criteria. The clinical histories of these 87 patients were analyzed. The age at initial vaccination ranged from 11 to 19 years old (mean \pm SD: $13.5 \pm 1.5$ years old), and the age at the first appearance of symptoms ranged from 12 to 20 years old (mean \pm SD: $14.3 \pm 1.6$ years old). The patients received an initial HPV vaccine injection between May 2010 and May 2013, but the first affected patient developed symptoms in October 2010, and the last affected developed symptoms in October 2015. A cluster of patients with a post-HPV vaccination disorder has not appeared in Japan during the last five years. Our study shows that, in Japan, the period of HPV vaccination considerably overlapped with that of a unique post-HPV vaccination disorder development. This disorder appears as a combination of orthostatic intolerance, chronic regional pain syndrome, and cognitive dysfunction, but its exact pathogenesis remains unclear.
\end{abstract}

Keywords: human papillomavirus vaccination; adverse effects; orthostatic dysregulation; chronic regional pain syndrome; cognitive dysfunction

\section{Introduction}

The human papillomavirus (HPV) infection plays a crucial role in the development of uterine cervical cancers [1]. Therefore, in May 2010, HPV vaccines, Cervarix ${ }^{\circledR}$ (GlaxoSmithKline, Brentford, UK), a papillomavirus recombinant bivalent vaccine, and Gardasil ${ }^{\circledR}$ (Merck \& Co, Inc., Kenilworth, NJ, USA), a papillomavirus recombinant quadrivalent vaccine, were widely introduced to Japanese female teenagers [2,3]. Beginning April 2013, female adolescents aged 13-16 years were legally required to receive this vaccination. Soon after this vaccination program began, a significant number of the vaccinated females complained of a unique disorder that was composed of violent tremulous involuntary movement, chronic pain, and weakness in the limbs. The Japanese mass media largely reported that a combination of these symptoms was previously unexperienced, suggesting that this disorder was a possible adverse reaction to HPV vaccination. Repeated presentations of suffering vaccinated females on television had a strong impact on Japanese society, 
forcing the Japanese Ministry of Public Health, Labour and Welfare to withdraw the recommendation for the use of HPV vaccination at the end of June 2013 [4]. Simultaneously, a special committee was organized to investigate the affected Japanese females, and our institution has been functioning as one of the investigation centers for the past eight years.

In our previous two reports [5,6], we described the clinical features and diagnostic criteria of the involved Japanese females with post HPV vaccination disorder. This disorder seems to include orthostatic dysregulation, chronic regional pain syndrome (CRPS), and cognitive dysfunction [5-7]. Post-vaccination abnormal autoimmune reactions are surmised to be responsible for this disorder [8,9], but a causal link has not been established between HPV vaccination and the appearance of these symptoms. Therefore, in this study, we attempted to clarify the temporal relationship between HPV vaccination and the development of this peculiar disorder on the basis of our single center's long-term observation of the affected Japanese females.

\section{Materials and Methods}

Between June 2013 and March 2021, we examined the symptoms and objective findings of $200 \mathrm{HPV}$ vaccinated female patients. According to our proposed diagnostic criteria [6], we obtained the necessary patient information, paying special attention to the duration between vaccination and the development of the first symptoms suspected to be related to the vaccine. The patients underwent physical and neurological examinations and routine laboratory tests. Skin temperature and a digital plethysmogram were recorded, and if necessary, the Schellong test was conducted. Moreover, neuropsychological tests and functional brain imaging were performed in patients with cognitive dysfunction. The details of these methods are described in our previous reports $[5,6]$. The study protocol was approved by the Institutional Review Board (approval nos. 4128 and 4150) of Shinshu University School of Medicine, Matsumoto, Japan.

\section{Results}

During the past eight years, 200 female patients visited our hospital with the suspicion of HPV vaccine-related adverse effects (33 patients in 2013, 43 in 2014, 38 in 2015, 49 in 2016, 25 in 2017, 8 in 2018, 4 in 2019, 0 in 2020, 0 in 2021). Of these, we excluded 19 patients who had symptoms before vaccination and 5 who received the HPV vaccine after 30 years of age. An additional 28 patients whose symptoms or disorders were explained by known diseases or who had abnormal laboratory data were also excluded, specifically, eight with epilepsy, six with psychiatric or anxiety disorders, three with systemic lupus erythematosus, one with juvenile idiopathic arthritis, one with anti-SGPS antibody-positive polymyositis, and nine with other diseases. For the remaining 148 patients, the clinical manifestations and objective findings were analyzed. The results showed that 32 patients were diagnosed with definite vaccine-related symptoms, and 55 were diagnosed with probable vaccine-related symptoms. The patient's symptoms and signs of the 87 patients diagnosed are summarized in Table 1. The most frequent symptom was prolonged general fatigue, which led to an inability to wake up and subsequently go to school in the morning. Severe headache, widespread pain involving the limbs and trunk, and dysautonomic symptoms including orthostatic fainting and bowel dysfunction were also responsible for markedly decreased daily activity in the patients. Further, widespread pain typically appeared as migratory joint pain without any signs of inflammation, and intermittent neuralgic pain in the chest or abdominal wall was common. Motor dysfunction showed variable patterns, but the distal dominant weakness of the limbs, which was mimicking that of polyneuropathy, was predominant. Abnormal sensations were mainly observed in the thighs or lower legs where dysesthesia or allodynia was frequent. As compared with these symptoms, learning impairment and sleep disorder developed later. The patients complained of a lack of mental clarity. Objective findings that were frequently observed were orthostatic dysregulation, including postural orthostatic tachycardia syndrome (POTS), abnormal 
digital plethysmogram recordings, and abnormalities on brain SPECT images. The details of these findings have been described in a previous report [6].

Table 1. Frequency of symptoms and signs in the 87 patients studied.

\begin{tabular}{ccc}
\hline Symptoms & Number of Cases & Frequency (\%) \\
\hline General fatigue & 73 & 83.9 \\
\hline Severe headache & 72 & 82.8 \\
\hline Widespread pain & 71 & 81.6 \\
\hline Dysautonomic symptoms & 71 & 81.6 \\
\hline Motor dysfunction & 56 & 64.4 \\
\hline Abnormal sensation & 52 & 59.8 \\
\hline Learning impairment & 52 & 59.8 \\
\hline Sleep disturbance & 44 & 50.6 \\
\hline Menstrual abnormality & 44 & 50.6 \\
\hline Limb shaking & 41 & 47.1 \\
\hline
\end{tabular}

The temporal distribution of the period of initial vaccination and the appearance of the first symptom in the diagnosed 87 patients is shown in Figure 1. Note that the initial vaccination period ranged from May 2010 to May 2013, and the age at initial vaccination ranged from 11 to 19 years old (mean \pm SD: $13.5 \pm 1.5$ years old). Meanwhile, the first symptom appeared from October 2010 to October 2015, and the age at the appearance of the first symptoms ranged from 12 to 20 years old (mean \pm SD: $14.3 \pm 1.6$ years old). Thus, the time from the first vaccine dose to symptom onset ranged from 0 to 1532 days (median: 199 days). The interval between the onset of symptoms and our initial examination ranged from 0 to 85 months (median: 31 months), indicating the illness duration in the patients before they visited our center.

The temporal relationship between the HPV vaccination and the development of the symptoms was as follows: the first HPV vaccine injection was in May 2010 and the last was in May 2013 (Figure 1a). The first affected vaccinated female developed symptoms in October 2010, and the latest appearance of symptoms occurred in two patients in October 2015; the peak period of the first injection of HPV vaccine seems to be between July 2011 and September 2012, and that of the development of unique post-vaccinated symptoms appeared between September 2011 and August 2013 (Figure 1a,b). Over the previous five years, we did not examine any patients who were newly affected by these unique symptoms (Figure 1b). 

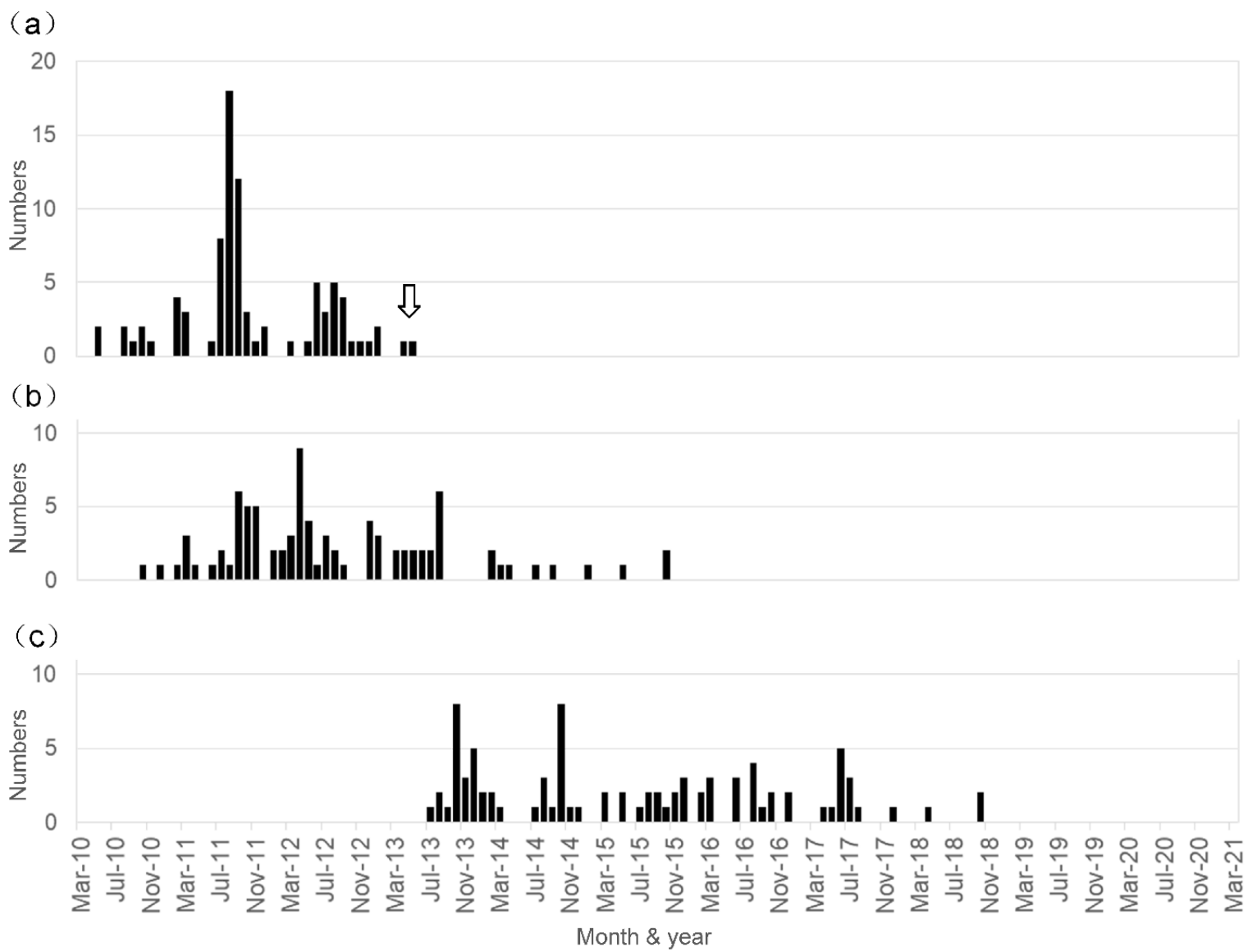

Figure 1. Temporal relationship between HPV vaccination and the development of symptoms in the patients diagnosed as having HPV vaccine-related symptoms. The period presented here ranged from May 2010 to March 2021. (a) Number of patients who received the first injection of HPV vaccine each month. The arrow indicates the time when the Japanese Ministry of Public Health, Labour and Welfare stopped the recommendation of HPV vaccination. (b) Number of patients who developed symptoms each month. (c) Number of patients who visited our institution and were diagnosed as having a post-HPV vaccination disorder each month.

\section{Discussion}

HPV vaccine safety has been reported in HPV vaccination-predominant countries [10-12]. Especially in Australia, although syncope occasionally occurs after HPV vaccination, the frequency of other serious adverse effects including POTS, CRPS, primary ovarian insufficiency, Guillain-Barré syndrome, autoimmune diseases, and venous thrombosis is very low, suggesting no causal association [13]. However, the potential risk of HPV vaccination and dysautonomia, CRPS, and chronic fatigue syndrome has been identified based on a series of case reports from different countries [14-19]. Thus, safety concerns regarding HPV vaccines remain controversial [20].

According to the reports of a Japanese special committee [21,22], 3.39 million Japanese females received HPV vaccinations between May 2010 and November 2016, and 2024 recipients were reported to have adverse reactions, of which 673 experienced serious symptoms. However, the incidence of adverse reactions in this vaccination period was determined to be low and insignificant, even though similar symptoms were not observed as a result of other vaccines.

Variable clinical manifestations in the post-HPV vaccination disorders can be explained by a combination of orthostatic dysregulation, mainly appearing as POTS, CRPS, and/or cognitive dysfunction $[5,6,23]$. Recent research has found that among POTS, CRPS, and myalgic encephalomyelitis/chronic fatigue (ME/CFS), some conditions overlap [24-26]; especially for cognitive dysfunction, slow thinking, difficulty in focusing, 
lack of concentration, forgetfulness, and confusion are commonly observed in all three disorders, and correspond to haziness in thought process, which is currently called "brain fog" [27]. Thus, the cognitive dysfunction observed in patients with post-HPV vaccination disorders may be a secondarily induced pathological condition following the long-lasting POTS and/or CRPS. Furthermore, POTS, CRPS, and ME/CFS seem to share similar autoimmune abnormalities [28], and a few preliminary studies [29-33] and case reports [34-37] have shown that the presence of serum autoantibodies against autonomic nerve receptors may be a critical determinant in the pathogenesis of these three disorders. In relation to this hypothesis, we investigated the autoantibodies against autonomic nerve receptors in the serum of the affected patients and revealed that the serum levels of autoantibodies against the adrenergic receptors and muscarinic acetylcholine receptors were significantly elevated in patients with HPV vaccination, as compared with those in the controls [38]. However, there was no statistically significant association between the clinical symptoms and elevated serum levels of these autoantibodies. Thus, further studies are required to consider the possibility of HPV vaccination-related abnormal autoimmune reactions.

In our previous report [6], we described a close temporal relationship between HPV vaccine administration and the appearance of possible adverse symptoms in 72 Japanese patients on the basis of four years of observation. In this study, we extended this observation period to nearly eight years, and the number of patients diagnosed was increased to 87, reaffirming that the period of HPV vaccination considerably overlapped with that of a unique post-vaccination disorder development in our country. In Japan, HPV vaccine coverage for females aged 12 to 16 years has dropped to less than $1 \%$ after the termination of the government's recommendation [39], and during the previous three years, few females visited us for evaluations regarding a suspected post-HPV-vaccination disorder. These observations indicate that intensive injections of HPV vaccines between May 2010 and May 2013 induced a cluster of Japanese patients with a unique post-HPV vaccination disorder. Japan is not the only exceptional country for an extremely lowered rate of HPV vaccination in recent several years; Latin American countries, such as Columbia, followed a similar pattern [40]. Adverse reactions to HPV vaccines seem to be influenced by different genetic backgrounds, cultural, and/or religious conditions. These conditions with no evidence of abnormal radiological images or laboratory data are often difficult to diagnose, easily leading to a pitfall of making the diagnosis of psychiatric illness.

Nevertheless, while there is a possible occurrence of adverse effects after HPV vaccination, these results do not necessarily signal the negation of the usefulness of this vaccine for the prevention of uterine cervical cancer [41]. If the information reported in this study is provided and is widely available at the induction of HPV vaccines, a social distaste for HPV vaccination (All Japan Coordinating Association of HPV Sufferers) would likely not occur in Japan. HPV vaccines are prophylactic and are not therapeutic, and thus, serious adverse effects are not acceptable, even if their incidences are low. Wide monitoring and an open discussion are recommended to ensure the safe announcement of HPV vaccines [42].

Author Contributions: Conceptualization, A.H. and S.-I.I.; designed this study, A.H. and S.-I.I.; analyzed the data, A.H.; writing the manuscript, A.H. and S.-I.I. Both authors have read and agreed to the published version of the manuscript.

Funding: This work was supported by the grant from a Health and Labour Science Research Grant on Emerging and Re-emerging Infectious Diseases (Establishment of Diagnosis and Treatment System on Symptoms after HPV vaccination, grant number 19HA1006) to S.-I.I. from the Ministry of Public Health, Labour and Welfare, Japan.

Institutional Review Board Statement: The study was conducted according to the guidelines of the Declaration of Helsinki and approved by the Institutional Review Board (approval nos. 4128 and 4150) of Shinshu University School of Medicine, Matsumoto, Japan.

Informed Consent Statement: Informed consent was obtained from all subjects involved in the study.

Data Availability Statement: Not applicable. 
Conflicts of Interest: The authors declare no conflict of interest directly relevant to the content of this study.

\section{References}

1. Walboomers, J.M.; Jacobs, M.V.; Manos, M.M.; Bosch, F.X.; Kummer, J.A.; Shah, K.V.; Snijders, P.J.; Peto, J.; Meijer, C.J.; Muñoz, N. Human papillomavirus is a necessary cause of invasive cervical cancer worldwide. J. Pathol. 1999, 189, 12-19. [CrossRef]

2. FUTURE II Study Group. Quadrivalent vaccine against human papillomavirus to prevent high-grade cervical lesions. N. Engl. J. Med. 2007, 356, 1915-1917. [CrossRef] [PubMed]

3. Jeurissen, S.; Makar, A. Epidemiological and economic impact of human papillomavirus vaccines. Int. J. Gynecol. Cancer 2009, 19, 761-771. [CrossRef] [PubMed]

4. The Ministry of Health, Labour and Welfare. Available online: http://www.mhlw.go.jp/bunya/kenkou/kekkaku-kansenshou2 8/pdf/kankoku_h25_6_01.pdf (accessed on 8 June 2021). (In Japanese)

5. Kinoshita, T.; Abe, R.; Hineno, A.; Tsunekawa, K.; Nakane, S.; Ikeda, S. Peripheral sympathetic nerve dysfunction in adolescent Japanese girls following immunization with the human papillomavirus vaccine. Intern. Med. 2014, 53, 2185-2200. [CrossRef]

6. Ozawa, K.; Hineno, A.; Kinoshita, T.; Ishihara, S.; Ikeda, S. Suspected adverse effects after human papillomavirus vaccination: A temporal relationship between vaccine administration and the appearance of symptoms in Japan. Drug Saf. 2017, 40, 1219-1229. [CrossRef] [PubMed]

7. Martínez-Lavín, M.; Amezcua-Guerra, L. Serious adverse events after HPV vaccination: A critical review of randomized trials and post-marketing case series. Clin. Rheumatol. 2017, 36, 2169-2178. [CrossRef] [PubMed]

8. Blitshetyn, S.; Brinth, L.; Hendrickson, J.E.; Martínez-Lavín, M. Autonomic dysfunction and HPV immunization: An overview. Immunol. Res. 2018, 66, 744-754. [CrossRef]

9. Hirai, T.; Kuroiwa, Y.; Hayashi, T.; Uchiyama, M.; Nakamura, I.; Yokota, S.; Nakajima, T.; Nishioka, K.; Iguchi, Y. Adverse effects of human papillomavirus virus vaccination on central nervous system: Neuro-endocrinological disorders of hypothalamo-pituitary axis. Auton. Nerv. Syst. 2016, 53, 49-64. [CrossRef]

10. Larson, H. The world must accept that HPV vaccine is safe. Nature 2015, 528, 9. [CrossRef]

11. Hviid, A.; Svanström, H.; Schekker, N.M.; Grönlund, O.; Pasternak, B.; Arnheim-Dahlström, L. Human papillomavirus vaccination of adult women and risk of autoimmune and neurological diseases. J. Intern. Med. 2017, 283, 154-165. [CrossRef]

12. Phillips, A.; Patel, C.; Pillsbury, A.; Brotherton, J.; Macartney, K. Safety of human papillomavirus vaccines: An updated review. Drug Saf. 2018, 41, 329-346. [CrossRef]

13. Phillips, A.; Hickie, M.; Totterdell, J.; Brotherton, J.; Dey, A.; Hill, R.; Snelling, T.; Macartney, K. Adverse events following HPV vaccination: 11 years of surveillance in Australia. Vaccine 2020, 38, 6038-6046. [CrossRef]

14. Blitshteyn, S. Postural tachycardia syndrome following human papillomavirus vaccination. Eur. J. Neurol. 2014, 21, 135-139. [CrossRef]

15. Brinth, L.; Theibel, A.C.; Pors, K.; Mehlsen, J. Suspected side effects to the quadrivalent human papillomavirus vaccine. Dan. Med. J. 2015, 62, A5064. [PubMed]

16. Brinth, L.S.; Pors, K.; Theibel, A.C.; Mehlsen, J. Orthostatic intolerance and postural tachycardia syndrome as suspected adverse effects of vaccination against human papillomavirus. Vaccine 2015, 33, 2602-2605. [CrossRef]

17. Palmieri, B.; Poddighe, D.; Vadalà, M.; Laurino, C.; Carnovale, C.; Clementi, E. Severe somatoform and dysautonomic syndromes after HPV vaccination: Case series and review of literature. Immunol. Res. 2017, 65, 106-116. [CrossRef]

18. Martínez-Lavín, M. Fibromyalgia-like illness in 2 girls after human papillomavirus vaccination. J. Clin. Rheumatol. 2014, 20, 392-393. [CrossRef] [PubMed]

19. Martinez, P. Motor and Sensory Clinical Findings in Girls Vaccinated against the Human Papillomavirus from Carmen de Bolivar, Colombia. Available online: https:/ / pompiliomartinez.wordpress.com/2016/03/04/motor-and-sensory-clinical-findings-ingirls-vaccinated-against-the-human-papillomavirus-from-carmen-de-bolivar-colombia/ (accessed on 8 June 2021).

20. Chandler, R.E. Safety concerns with HPV vaccines continue to linger: Are current vaccine pharmacovigilance practices sufficient? Drug Saf. 2017, 40, 1167-1170. [CrossRef] [PubMed]

21. The Ministry of Health, Labour and Welfare. Available online: http://www.mhlw.go.jp/file/05-Shingikai-10601000 -Daijinkanboukouseikagakuka-Kouseikagakuka/0000161349.pdf (accessed on 8 June 2021). (In Japanese)

22. The Ministry of Health, Labour and Welfare. Available online: http://www.mhlw.go.jp/file/05-Shingikai-10601000 -Daijinkanboukouseikagakuka-Kouseikagakuka/0000161329.pdf (accessed on 8 June 2021). (In Japanese)

23. Matsudaira, T.; Takahashi, Y.; Matsuda, K.; Ikeda, H.; Usui, K.; Obi, T.; Inoue, Y. Cognitive dysfunction and regional cerebral blood flow changes in Japanese females after human papillomavirus vaccination. Neurol. Clin. Neurosci. 2016, 4, 220-227. [CrossRef]

24. Stewart, J.M. Autonomic nervous system dysfunction in adolescents with postural orthostatic tachycardia syndrome and chronic fatigue syndrome is characterized by attenuated vagal baroreflex and potentiated sympathetic vasomotion. Pediatr. Res. 2000, 48, 218-226. [CrossRef]

25. Karas, B.; Grubb, B.P.; Boeth, K.; Kip, K. The postural orthostatic tachycardia syndrome: A potentially treatable cause of chronic fatigue, exercise intolerance, and cognitive impairment in adolescents. Pacing Clin. Electrophysiol. 2000, 23, 344-351. [CrossRef] [PubMed] 
26. Halicka, M.; Vittersø, A.D.; Proulx, M.J.; Bultitude, J.H. Neuropsychological changes in complex regional pain syndrome (CRPS). Behav. Neurol. 2020, 2020, 4561831. [CrossRef]

27. Ocon, A.J. Caught in the thickness of brain fog: Exploring the cognitive symptoms of chronic fatigue syndrome. Front. Physiol. 2013, 4, 63. [CrossRef] [PubMed]

28. Meyer, C.; Heidecke, H. Antibodies against GPCR. Front Biosci. 2018, 23, 2177-2194.

29. Yub, X.; Stavrakis, S.; Hill, M.A.; Huang, S.; Reim, S.; Lin, H.; Khan, M.; Hamlett, S.; Cunningham, M.W.; Kem, D.C. Autoantibody activation of beta-adrenergic and muscarinic receptors contributes to an "autoimmune" orthostatic hypotension. J. Am. Soc. Hypertens. 2012, 6, 40-47. [CrossRef]

30. Ruzieh, M.; Batizy, L.; Dasa, O.; Oostra, C.; Grubb, B. The role of autoantibodies in the syndromes of orthostatic intolerance: A systemic review. Scand. Cardiovasc. J. 2017, 51, 243-247. [CrossRef] [PubMed]

31. Kohr, D.; Singh, P.; Tschernatsch, M.; Kaps, M.; Pouokam, E.; Diener, M.; Kummer, W.; Birklein, F.; Vincent, A.; Goebel, A.; et al. Autoimmunity against the $\beta 2$ adrenergic receptor and muscarinic-2 receptor in complex regional pain syndrome. Pain 2011, 152, 2690-2700. [CrossRef]

32. Dubuis, E.; Thompson, V.; Leite, M.I.; Blaes, F.; Maihofner, C.; Greensmith, D.; Vincent, A.; Shenker, N.; Kuttikat, A.; Leuwer, M.; et al. Longstanding complex regional pain syndrome is associated with activating autoantibodies against alpha-1a adrenoreceptors. Pain 2014, 155, 2408-2417. [CrossRef]

33. Loebel, M.; Grabowski, P.; Heidecke, H.; Bauer, S.; Hanitsch, L.G.; Wittke, K.; Meisel, C.; Reinke, P.; Volk, H.D.; Fluge, Ø.; et al. Antibodies to $\beta$ adrenergic and muscarinic cholinergic receptors in patients with chronic fatigue syndrome. Brain Behav. Immun. 2016, 52, 32-39. [CrossRef] [PubMed]

34. Hendrickson, J.E.; Hendrickson, E.T.; Gehrie, E.A.; Sidhe, D.; Wallukat, G.; Schimke, I.; Tormey, C.A. Complex regional pain syndrome and dysautonomia in a 14-year-old girl responsive to therapeutic plasma exchange. J. Clin. Apher. 2016, 31, 368-374. [CrossRef]

35. Hendrickson, J.E.; Tormey, C.A. Human papilloma virus vaccination and dysautonomia: Consideration for autoantibody evaluation and HLA typing. Vaccine 2016, 34, 4468. [CrossRef]

36. Blitshteyn, S.; Brook, J. Postural tachycardia syndrome (POTS) with anti-NMDA receptor antibodies after human papillomavirus vaccination. Immunol. Res. 2017, 65, 282-284. [CrossRef] [PubMed]

37. Schofield, J.R.; Hendrickson, J.E. Autoimmunity, autonomic neuropathy, and the HPV vaccination: A vulnerable subpopulation. Clin. Pediatr. 2018, 57, 603-606. [CrossRef] [PubMed]

38. Hineno, A.; Ikeda, S.; Scheibenbogen, C.; Heidecke, H.; Schulze-Forster, K.; Junker, J.; Riemekasten, G.; Dechend, R.; Dragun, D.; Shoenfeld, Y. Autoantibodies against autonomic nerve receptors in adolescent Japanese girls after immunization with human papillomavirus vaccine. Ann. Arthritis Clin. Rheumatol. 2019, 2, 1014.

39. Simms, K.T.; Hanley, S.J.B.; Smith, M.A.; Keane, A.; Canfell, K. Impact of HPV vaccine hesitancy on cervical cancer in Japan: A modelling study. Lancet Public Health 2020, 5, e223-e234. [CrossRef]

40. Cervantes, J.L.; Doan, A.H. Discrepancies in the evaluation of the safety of the human papillomavirus vaccine. Mem. Inst. Oswaldo Cruz 2018, 113, e180063. [CrossRef] [PubMed]

41. Chambuso, R.S.; Rebello, G.; Kaambo, E. Personalized human papillomavirus vaccination for persistence of immunity for cervical cancer prevention: A critical review with experts' opinions. Front. Oncol. 2020, 10, 548. [CrossRef] [PubMed]

42. Wick, G. Allowing an Open Discussion of the Side Effects of Vaccines. Available online: https://science.sciencemag.org/content/ allowing-open-discussion-side-effects-vaccines (accessed on 8 June 2021). 